\title{
Tornar discutível: tratamento político de uma herança tecnológica*
}

\section{Rendre discutable: \\ le traitement politique d'un héritage technologique}

\section{Making things debatable: the political treatment of a technological lock-in}

\author{
Yannick BARTHE**
}

\begin{abstract}
RESUMO
Os procedimentos de consulta que têm se desenvolvido há alguns anos no domínio das ciências e das técnicas são geralmente denunciados como meras formas de manipulação dos cidadãos para legitimar decisóes já tomadas. Esta percepção não dá conta, no entanto. do caráter freqüentemente ambivalente deste tipo de procedimento que, além de canalizar as controvérsias, tem por resultado aumentar a "discutibilidade" dos problemas e explicitar concretamente o rol de escolhas possíveis. Assim. a partir do caso das audiências públicas organizadas em 1990 pelo Parlamento francês sobre a questão da estocagem dos dejetos nucleares, este artigo mostra como um dispositivo de consulta pode tanto contribuir para dar os parâmetros para a controvérsia como para abrir a "caixa-preta" das decisóes técnicas consideradas a priori como irreversíveis.

Palavas-chave: consultas públicas sobre riscos ambientais; estocagem de dejetos nucleares: discussão da tecnologia
\end{abstract}

\section{RÉSUMÉ}

Les procédures de consultation qui fleurissent depuis quelques années dans le domaine des sciences el des techniques sont généralement dénoncées comme étant de simples techniques de manipulation des gouvernés visant à légitimer des décisions déjà prises. Une telle vision ne rend toutefois pas compte du caractère souvent ambivalent de ce type de procédures qui. tout en permettant de canaliser les controverses. ont pour résultat d'augmenter la «discutabilité» des problèmes et d'ouvrir concrètement l'éventail des choix possibles. Ainsi, à partir du cas des auditions publiques organisées en 1990 par le Parlement français sur

* Agradeço a Bruno Jobent, Cyril Lemieux e Rachel Vanneuville pelos comentários que fizeram sobre uma versão anterior deste

**Tradução feita pela doutora Gaby Friess Kirsch, professora do DELEM - Universidade Federal do Paraná. 
la question du stockage des déchets nucléaires. cet article montre comment un dispositif de consultation peut tout à la fois contribuer à encadrer une controverse et avoir pour effet d'ouvrir la «boîte noire» de décisions techniques pourtant considérées comme irréversibles.

Mots-clé: consultations publiques sur les risques environnementales : stockage des déchets nucléaires :discussions sur la technologie

\title{
ABSTRACT
}

\begin{abstract}
The consulting procedures that have been growing for a few years in the sciences and technologies lields are usually declared as being simple tools of conjuring from the rulers in order to justify decisions already taken. However, such a point of view doesn't show the character often ambivalent of this type of procedures, which can canalise the controversy, but can also increase the "debatability" and open the space of possible choices. Like this, starting from the public hearings organised in 1990 by the French Parliament about the nuclear wastes storage, this article shows, on the one hand, the way a consultation purview can contribute to enclose a controversy. and on the other hand acts like opening the "black box" of some technological decisions eventhough considered as irreversible.
\end{abstract}

Key-words: consulting procedures on environmental risks; nuclear wastes storage: discussing technology:

O entusiasmo atual pela deliberação chegou a tal ponto que, de agora em diante, é freqüente vermos desenvolverem-se dispositivos de consulta em terrenos que acreditávamos estéreis. Assim, as políticas da ciência e da tecnologia tornaram-se, no intervalo de alguns anos, espaços prediletos de um certo número de inovações processuais no que diz respeito à abertura participativa e ao debate público.' $\mathrm{O}$ fenômeno atinge até os setores antigamente considerados os mais reticentes a esse tipo de método e que, como o setor nuclear na França, concentram tradicionalmente o potencial mais forte de fechamento dos debates sobre a direção das políticas públicas. ${ }^{2}$ Não obstante, essas iniciativas muitas vezes intervêm justamente em situações nas quais nada mais pode ser discutido. Na verdade, alguns projetos tecnológicos contestados hoje em dia, nada mais são que o resultado de uma longa série de escolhas passadas que parecem irreversíveis; apresentam-se, em primeiro lugar, como heranças históricas incontornáveis. As políticas tecnológicas são também marcadas por processos de irreversibilização que acabam gerando o que os economistas da mudança técnica chamam situações de "trancamento" (lock-in):" com o tempo, houve ramificações, editaram-se normas, aprovaram-se investimentos, todos fatores que contribuíram para restringir singularmente o espaço das escolhas possíveis e criar uma forte dependência do caminho inicialmente trilhado. Resulta disso que as controvérsias públicas que se tra-

1 No decorrer da última decada, uma ampla literatura foi produzida sobre o assumto. Para um apanlado, ver .JOSS, S.: DURAND, J. (Eds.). P'ublic /'arlicipallon in Sicrence. The Role of Consensus Conferences in Europe. London: Science Museum, 1995: RENN, O.: WEBLIER, T: WIEDEMANN, P. (Eds.). Iarmexir and

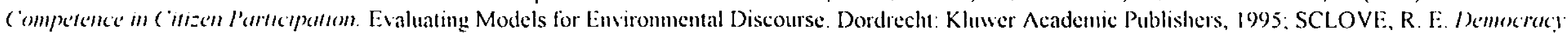

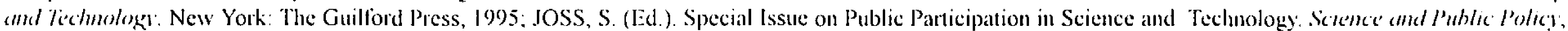

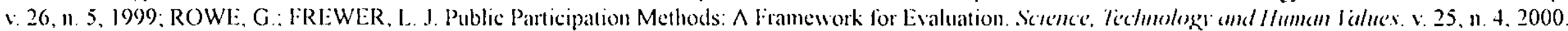

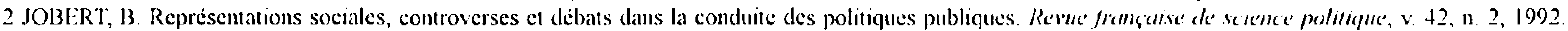
3 ARTHUR, B. W. Compeling Teclunologies, Increasing Returns, and Lock-in by llistorical Events. The licomomic . Jommal, n. 99. I989. Sobre os procedimentos

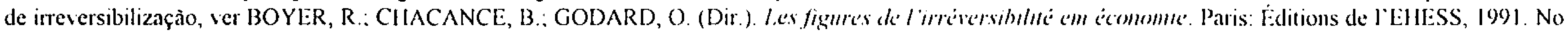
que diz respeito mais especificamente à energia nuclear, ver COWAN, R. Nuclear Power Reactors: A Study in Teclunological Lock-in. . onumal of licomomic //Istory,

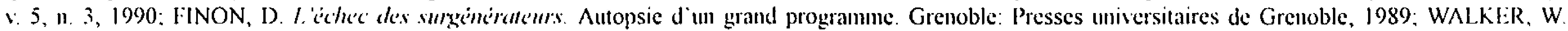
Entrapment in Large Technology Systems: Institutional Commitment and Power Relations. Rescurch lolicy, v. 29, n. 7-8, 2000.

4 Após o artigo pioneiro de DAVID, P. Clio and the Economics of QWERTY. fmericam licomomic Ro'vicu', n. 75, 1985, um sem-numero de estudos em economia da inovaçào enfocaram a multiplicidade dos fatores suscetiveis de fivorecer esses fenômenos de "dependência da trillıa" (palh depenckence). Desde entào, a noção de palh dependence foi transferida para a ciencia politica, notadamente, pelo vies dos trabalhos de Paul Pierson (PIERSON, P. When Effec Becomes Cause: P'olicy

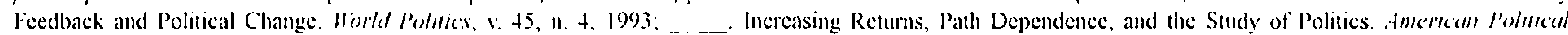

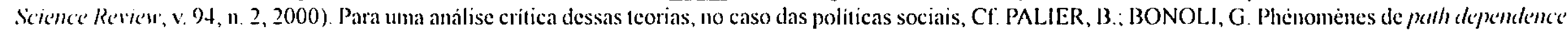

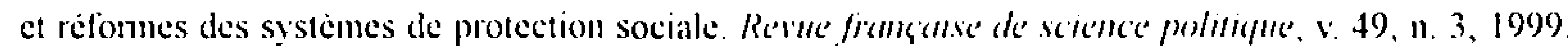


vam atualmente em torno de certos projetos tecnológicos chegam, em muitos casos, "depois do embate", quer dizer, depois que as grandes orientações foram fixadas."

A importância dessa dimensão temporal explica, em parte, o ceticismo geralmente alimentado diante dos processos consultivos, regularmente denunciados como meros disfarces destinados a legitimar a posteriori decisões já ratificadas. Por trás de uma retórica que elogia os progressos da democracia deliberativa, teríamos, na verdade, um sutil empreendimento de controle social, um novo artifício do governo para tentar emprestar um verniz democrático aos desígnios inalterados de uma elite tecnocrática toda poderosa. Ainda que pareça um tanto forçado, essa "tese da inocuidade" não deixa de aflorar na maioria das críticas formuladas contra os processos consultivos e o debate público, uma tese cujas motivações Albert Hirschman revelou." Longe de ser o privilégio dos julgamentos espontâneos que podem ser emitidos pelos atores no fogo cruzado das controvérsias, essa linha de argumentação exerce seu poder de sedução sobre um sem-número de especialistas em ciências sociais empenhados nessas questões, os quais enfocam, além das mudanças aparentes, a estabilidade das relações de força e a supremacia dos interesses constituidos. ${ }^{7}$

Essa postura tem o mérito de destruir o retrato idílico que às vezes se faz dos dispositivos de consulta, mas, por outro lado, apresenta a desvantagem de propor uma visão demasiado redutora destes. Em primeiro lugar, o esquema da ação manipuladora subestima o caráter "explorador" desse tipo de processos, que nunca são totalmente controlados por uma única categoria de atores. ${ }^{8}$ Como a sua possível instrumentalização não é reservada aos governantes nem aos promotores dos projetos, podem produzir efeitos inesperados, ainda que isso aconteça, é verdade, com uma defasagem temporal. Em seu trabalho precursor sobre as formas de regulamentação tecnológica, Michael Pollak ressaltou esse ponto ao descrever como a "exploração tática" de alguns processos administrativos pelos militantes contestadores alemães e norte-americanos contribuiu, a partir do fim da década de 70 , para alterar fortemente as políticas nucleares dos dois países." Em segundo lugar, a crítica de acordo com a qual os dispositivos de consulta teriam apenas a finalidade de produzir uma cortina de fumaça erra ao negligenciar seu próprio alcance político. Como observa Hirschman, "a grande crítica que se pode fazer à tese da inocuidade é que ela não leva suficientemente a sério nem o que afirma, nem a ação que ela própria exerce nos acontecimentos". " Portanto, é permitido pensar que o clima de suspeita generalizada que envolve os processos hoje em dia, especialmente quando são desenvolvidos em situações muito conflitantes, não deixa de produzir algum efeito sobre o seu andamento e seu resultado. A vigilância crítica dos grupos contestadores, que às vezes se alimenta da divulgação de certas análises de cunho sociológico, tem como resultado tornar mais custoso e arriscado o desrespeito aos princípios democráticos reivindicados pelas autoridades que tomam a iniciativa de uma consulta pública." Mas, além disso, é suscetivel de desencadear uma dinâmica de "auto-refutação": a denúncia dos desvios que podem

\footnotetext{
5 Por isso, alguns autores propuseram chamar esses conflitos controvérsias "pós-tecnológicas", Cf. CALLON, M. Pour une sociologie des controverses teclunologiques. Fundementa Sicremtice, v. 2, n. 3-4, 1981.

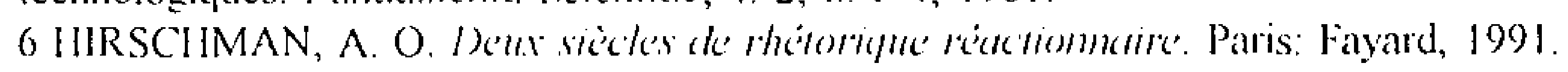

7 Pode-se achar boas ilustraçoes dessa postura em KEMP, R. Planning, Public llearings, and the Politics of Discourse. lu: FORESTER, J. (Ed.). ('ritical Theory and 'mblic Life. Cambridge: MIT Press, 1985; LEVIDOW, L. Democratizing Technology or Technologizing Democracy? Regulation Agricultural Biotechnology in Europe. Techmolege in Siocret! n. 20, 1998.

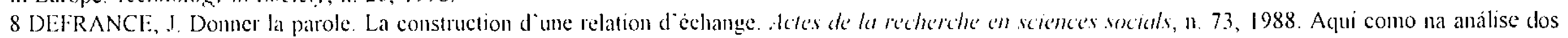
processos decisivos, reconlrecer os objetivos estratégicos que permeiam esses dispositivos "nào leva necessariamente a uma visào da realidade politica como mera exposiçào das intençóes de atores dotados de recursos institucionais", Cf. CORCUIF, P.: SANIER, M. Politique publique et action stratégique en contexte de décentralisation. Aperçus diun processus decisionnel après la bataille. Amales HSS, v. 55, $11.4,2000$.

9 POLLACK, M. La régulation tedunologique: le difficile mariage entre le droit et la technologie. Revine fremçaise de scrence politiche, v.32, n. 2, 1982. Vários trabalhos recentes que trataun de conllitos de ajuste resultan em conclusòes que seguem a mesma direção. Por exemplo, o traballho de Cécile Blatrix mostra de maneira convincente que, ao contrário de uma idéia ja aceita, os processos participatios nào levaram a um estreitancento do repertório de açào coletiva dos grupos

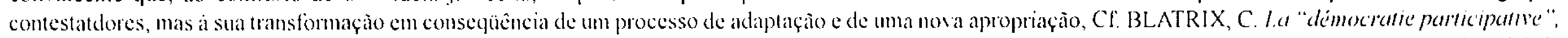
de man os am mohilhsamions ami-Thil. Processus de consolidation d'institutions sociales emergentes. Tese de doutoramento em Ciencia Politica, Universite de Paris 1, 2000

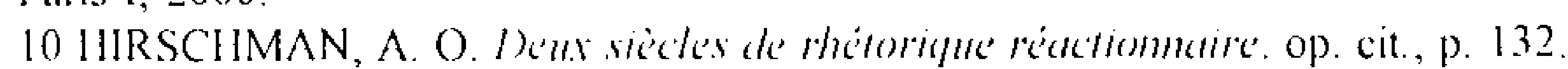

11 BI.ONDIAUX, I. La déliberation, nome de laction publique contemporaine? Projer, n. 268, 2001.
} 
existir entre um ideal de discussão pública e o recurso concreto aos processos consultivos criam então uma tensão que, ao mesmo tempo em que contribui para tornar a deliberação uma nova norma da ação política, leva os poderes públicos a se conformarem a elas, ainda que somente para garantir as virtudes apaziguadoras geralmente atribuídas a esse tipo de dispositivo no tratamento dos conflitos.

Com estas últimas observações, começamos a entender melhor em que as controvérsias públicas que surgem nas situações de irreversibilidade técnica evocadas acima constituem uma verdadeira prova para os dirigentes políticos, que se vêem obrigados a romper com as práticas autoritárias, a providenciar espaços de discussão, a efetuar uma mudança, que, mesmo que desejável a seus olhos, não deixa de estar comprometida de antemão devido à falta de alternativa no plano técnico. Em outras palavras, os responsáveis políticos se vêem confrontados com a necessidade de provar sua capacidade de governar ainda que o peso do passado e a conseqüente redução do espaço de escolha pareçam ter suprimido as decisões para a ação política e, no caso, para a implementação de processos deliberativos. ${ }^{12}$ Como, em tais situações, dar credibilidade à abertura de um espaço de discussão? Como "tornar governável"' esse tipo de situação na qual as margens de manobra parecem ser tão restritas que hipotecam qualquer idéia de mudança? E esse paradoxo vai nos servir de chave de leitura para analisar o caso das consultas públicas organizadas em 1990 pela Comissão Parlamentar para Avaliação das Escolhas Científicas e Tecnológicas [Office parlementaire d'éraluation des choix scientifiques et techniques] a respeito da estocagem do lixo atômico. Esse caso é interessante por várias razões. Em primeiro lugar, e convém assinalá-lo logo, trata-se de um processo que será seguido de efeitos concretos em termos de decisões: as recomendações formuladas no fim da consulta serão, de fato, retomadas pelo governo e terão uma tradução legislativa com a votação de uma lei em 1991, que redefinirá substancialmente a política até então desenvolvida quanto ao manejo do lixo atômico. Porém, há mais do que isso: ao analisar o desenrolar desse processo, temos a oportunidade de abandonar uma esquematização fácil, que perpassa mais ou menos por grande parte da literatura relativa a esse tipo de dispositivo e que opõe, por um lado, uma lógica de gestão de conflito, e por outro lado, uma lógica deliberativa. $\mathrm{O}$ argumento que queremos defender, neste artigo, é, ao contrário, que essas duas dimensões são inseparáveis: se os processos consultivos podem ser apreendidos como "ferramentas de governabilidade" $\mid+$ particularmente eficientes, não é somente por permitirem estruturar os debates e canalizar os conflitos provocados por algumas decisões públicas, mas também, e talvez, sobretudo porque têm, como efeito, ao mesmo tempo, aumentar o que propomos chamar a sua discutibilidade, isto é, o grau em que essas questões são suscetiveis de ser submetidas a um regime de discussão pública. Ora, em situação de trancamento tecnológico, essa discussão apresenta o interesse maior de fazer emergir soluções alternativas, reconstituir um espaço de escolha e, correlativamente, restabelecer a figura do "decididor" político em áreas que pareciam ter-lhe escapado. No caso das consultas públicas sobre a estocagem do lixo atômico, vamos ver como se opera concretamente essa reapropriação política descrevendo, num primeiro momento, as principais caracteristicas desse processo, e, depois, em seguida, concentrando nossa atenção mais no produto da consulta. Antes, porém, de abordar o desenrolar das consultas, cabe dizer algo sobre as circunstâncias em que a Comissão Parlamentar para Avaliação das Escolhas Científicas e Tecnológicas foi levada a incumbir-se dessa questão.

\section{O enterramento do lixo atômico: uma solução} que se tornou "inevitável"

No fim da década de 80 , a estocagem do lixo radioativo não é mais um problema emergente. No decorrer das últimas décadas, a questão do que ia acontecer com os últimos resíduos do "ciclo" do combustível nuclear

12 Ora, como lembra Bemard Manin, o fato de existir uma escolha real entre värias saidas é uma das condiçoes necessarias para a deliberaçào. Cf MANIN, B. Volonté générale ou delibération? Esquisse d'une théorie de la délibération politique. $l$ ce léh ha, n. 33, 1985, p.89.

13 LASCOUMES, P. Rendre gouvemable: de la "traduction" au "Iranscodage". L'analyse des processus de changement dans les réseaux daction publique. In: CURAPP. (Ed.). la gonnernahilite. Paris: PUF, 1996.

14 BACHIR, M. La consultation politique. Nouvel outil de gouvernabilite et transformation des registres d action publique. In: FRANCYIS, B.: NEVEU, E. (Dir.). Espaces publics mosärumes. Acteurs, arènes et rhétoriques des de bats publics contemporains. Rennes: Presses universitaires de Rennes, 1999. 
foi regularmente levantada nas controvérsias que marcaram continuamente a história desse setor. Além disso, desde os primeiros passos da indústria atômica, graças a incentivos de organismos internacionais, como a Agência Internacional para a Energia Atômica (Aeia) ou a Agência para a Energia Nuclear da OCDEE (AEN), foi desenvolvido um sem-número de programas de pesquisa sobre o assunto e, a julgar pela diversidade das soluções propostas no decorrer da história, não é exagerado dizer que a inventividade e a imaginação foram, durante muito tempo, particularidades dessa área científica e técnica: evacuação espacial do lixo com o auxílio de foguetes, depósito nas zonas de subdução das placas oceânicas, enterramento nos sedimentos finos dos grandes fundos marinhos, destruição por irradiação de nêutrons; tantos foram os caminhos de pesquisa que receberam atenção durante algum tempo, antes de irem se juntar ao grande cemitério dos projetos tecnológicos abortados. Lentamente a imaginação se esgotou e essa diversidade tecnológica desvaneceu progressivamente para ceder lugar a uma solução considerada pela maioria dos especialistas como inevitável: o enterramento do lixo altamente radioativo e de longa vida em camadas geológicas profundas. $O$ interesse dessa solução é utilizar a estabilidade de certas formações geológicas, tais como o granito ou a argila, a fim de constituir uma "armadilha" situada a 400 metros de profundidade e capaz de isolar os radioelementos da biosfera por um prazo muito longo, após seus recipientes terem sido destruídos pela erosão. A estocagem geológica irreversível deve assim permitir que nos emancipemos progressivamente de qualquer forma de discussão quanto à evolução da sociedade e das suas instituições. As incertezas relativas quanto à capacidade das gerações futuras de vigiar os depósitos de lixo radioativo são substituídas pelas incertezas que envolvem o comportamento a longo prazo das formações geológicas a priori favoráveis, incertezas suscetíveis de serem domesticadas por meio dos cálculos e modelos de previsão estabelecidos pela "geologia prospectiva".

A orientação rumo a esse método de estocagem não se fez em um dia. Na França, como na maioria dos países confrontados com o problema, a solução do enterramento do lixo atômico adquiriu seu caráter "incontornável" em etapas. Entre outras opções de pesquisa no início da década de 70 , o projeto de estocagem geológico torna-se real pouco a pouco graças à sua grande capacidade de "endogenização" das limitações econômicas e políticas que pesam progressivamente sobre a gestão do lixo atômico. Menos dispendioso que outros procedimentos promissores, porém incertos, como as técnicas de transmutação que visam a reduzir a duração de vida de certos elementos radioativos, o enterramento também parece ser de implantação menos delicada que certas soluções que, como o depósito do lixo em meio submarino, suscitam forte oposição política nos fóruns internacionais, notadamente da parte dos países não-nuclearizados. De acordo com os dirigentes do programa nuclear, a estocagem geológica apresenta, além disso, a vantagem de solucionar definitivamente esse problema sensível sem que sejam questionadas certas escolhas constitutivas da "doutrina" do programa nuclear civil francês, tais como a concepção dos reatores e sobretudo o retratamento dos combustíveis irradiados. $^{15}$ Durante a década de 80 , a renúncia a caminhos de pesquisa alternativos, assim como o fato do CEA, então muito pouco dotado de recursos científicos, ter tomado para si o problema, criando a Agência Nacional pela Gestão do Lixo Radioativo (Andra), contribuem para "enrijecer" a orientação para a estocagem geológica. A questão deixa progressivamente o âmbito da pesquisa para se tornar um projeto industrial. De resto, em 1987, no momento em que são desenvolvidos estudos de reconhecimento geológico em quatro localidades selecionadas pelas propriedades de seu subsolo, a estocagem geológica não é mais verdadeiramente uma opção de pesquisa; é apresentada por seus promotores como uma solução estabelecida, cuja necessidade não poderia ser posta em dúvida, tendo como único risco fazer o futuro do lixo atômico parecer um problema não solucionado e, por isso mesmo, suscetível de tirar a credibilidade do conjunto dos canais oficiais.

Ora, é, justamente o caráter necessário e incontornável da estocagem geológica que vem sendo colocado no centro das controvérsias desencadeadas pelo anúncio brutal dos trabalhos da Andra. A perspectiva de implantação de um laboratório subterrâneo prefigurando um centro de estocagem em profundidade

15 BARRERE, M. La doctrine nucléaire contre vents et marées. In: FERME, G. (Dir.). Scicunc', poun'oir ct argent. La recherehé entre marché et politique. Paris: Autrement, 1993. (Série Sciences en société. 11. 7). 
suscita uma oposição maciça nos quatro departamentos selecionados. ${ }^{16}$ As associações de proteção do meio ambiente, auxiliadas pela maioria das autoridades locais, denunciam a falta de informação e de consulta prévias para a implementação do projeto, estigmatizam a opacidade do processo de decisão que levou à escolha das localidades e, mais fundamentalmente, questionam a pertinência de uma solução que, embora se apresente como uma "necessidade", deixa pairar amplas incertezas quanto à sua viabilidade a longo prazo. Durante três anos, os departamentos envolvidos passaram a ser o palco de embates ásperos e de conflitos frequientemente violentos, obrigando o governo a proclamar, em 1990, uma moratória de um ano sobre as pesquisas desenvolvidas pela Andra a fim de evitar uma possível ampliação da controvérsia e, desse jeito, conjurar o risco de questionamento mais global de uma indústria cuja imagem foi gravemente manchada pela catástrofe de Chernobyl. Preocupado em ostentar um estilo de governo no qual o diálogo e a busca de consenso são elevados a valores cardinais, Michel Rocard, o então primeiro-ministro, pretende punir a inadequação de um modo de ação pública apoiada essencialmente na imposição unilateral de uma decisão tomada de maneira reservada e sem consulta. Para solucionar o que parece primeiramente um problema de "aceitabilidade social", espontaneamente imputado a um déficit de "comunicação" e a uma falta de flexibilidade na implementação do projeto, o governo convida a Comissão Parlamentar para Avaliação das Escolhas Científicas e Tecnológicas (OPLCST) a incumbir-se dessa questão espinhosa. Criada em $1983 \mathrm{com}$ o objetivo de informar o Parlamento sobre as conseqüências das escolhas de caráter científico e tecnológico, essa delegação parlamentar comum à Assembléia Nacional e ao Senado é então encarregada de desenvolver uma "reflexão aprofundada com os representantes de todas as partes interessadas", a fim de "reexaminar serenamente as coisas". 17

\section{A construçấo de um espaço de discussão: um enqualramento da controvérsia}

Não é inútil lembrar as condições nas quais a questão do lixo atômico foi transmitida ao Parlamento para entender a maneira como são organizadas as consultas públicas conduzidas pela Comissão Parlamentar. Na verdade, a definição dos objetivos atribuídos aos processos consultivos, assim como sua organização, constituem desafios que variam muito segundo o contexto no qual são implementados. Isso se verifica ainda mais quando esses processos, como no caso das consultas públicas, não têm um verdadeiro estatuto jurídico e se articulam de maneira informal com o processo de implementação de uma política. Em alguns casos, o recurso a esse tipo de processos intervém como uma medida de acompanhamento de um projeto e pode ser iniciado pelos próprios promotores deste, que vêem nisso uma boa oportunidade de esclarecer suas mensagens, de fazer um trabalho pedagógico, ou ainda, de assinalar sua boa vontade, desviando-se claramente de práticas mais dirigistas. ${ }^{1 \times}$ A consulta é concebida então como um meio, se não de prever, pelos menos de canalizar os conflitos que possam provocar algumas decisões impopulares, aumentando sua legitimidade democrática. Porém, em outros casos, a implementação de um processo consultivo intervém uma vez desencadeado o conflito. Ela, então, não se inscreve mais em uma lógica de antecipação, mas, antes, em uma lógica "reativa": o processo consultivo assemelha-se então a um dispositivo que, por seu caráter excepcional, deve marcar uma franca ruptura com as práticas anteriores e permitir sair da "crise". Neste último caso, que nos interessa aqui, o debate quer ser "reparador", pois visa, antes de tudo, a "restabelecer a confiança entre governantes e governados, expondo ostensivamente a abertura dos governantes para a escuta, estabelecendo assim sua proximidade com a população"." O espaço de discussão constituído pelo dispositivo de consulta é distinguido, então, por três caracteristicas.

\footnotetext{
16 Tratava-se dos departamentos do Ain, das Deux-Sevres e do Maine-cl-Loire.

17 Communiqué du service de presse du Premier ministre, 9 fév. 1990. [Comunicalo do serviço de imprensa do Primeiro Ministro, 9 fev. 1990).

18 DEFRANCE, I. Iomme la parole. La construction d'une relation d'eclange ant cite (citado), p. 54.

19 CHAMBAT, P.: FOURNIAU, I.-M. Débat public et participation démocratique. In: VALL.EMONT (Dir). l.e dehat public: une réforme dans l'ktat. Paris: L. G. D. J., 2001 . p. 35
} 


\section{A produção de uma instância de arbitragem ou o elogio da ingenuidade}

O que caracteriza em primeiro lugar o processo das consultas públicas sobre a estocagem do lixo atômico é a postura de arbitragem endossada pelo organismo encarregado de organizar essa consulta. Não se concebe facilmente que uma instância parlamentar possa se apresentar com ares de neutralidade. O Parlamento, sabemos, foi freqüentemente analisado, pelo contrário, como um lugar de ampliação das controvérsias, como um tipo de caixa de ressonância, que tem como efeito dar um sentido explicitamente político a certos conflitos. ${ }^{21}$ Ora, ele aparece aqui, paradoxalmente, como um "terreno neutro", de que as paixões políticas parecem ter desertado. Composto de oito deputados e de oito senadores, a Comissão Parlamentar para Avaliação das Escolhas Científicas e Tecnológicas gosta de se apresentar como um organismo não partidário e capaz de fornecer um esclarecimento imparcial sobre os conflitos que permeiam o desenvolvimento das "tecnociências". No caso do lixo atômico, essa postura de arbitragem é possibilitada sobretudo graças a um "efeito de notoriedade" ou, melhor, a uma ausência de notoriedade nessa área. Na perspectiva de um desenlace do conflito, a modéstia do papel desempenhado historicamente pelo Parlamento na elaboração e no controle da politica nuclear francesa constitui, na verdade, antes um trunfo do que uma desvantagem. Por um lado, o simples fato de recorrer às instâncias parlamentares surge como uma idéia nova na área, permitindo estabelecer uma descontinuidade radical na história dessa política e, assim, satisfazer as exigências do incoativo." Por outro lado, supõe-se que a "inexperiência" das instâncias parlamentares no que diz respeito aos problemas colocados pela energia nuclear garanta a imparcialidade do processo consultivo implementado.

De forma análoga, a escolha do relator encarregado de organizar as consultas públicas também responde a essa exigência de imparcialidade. No âmbito da Comissão Parlamentar, não existe nenhum processo formal que permita designar aquele que será encarregado da tarefa de fazer uma investigação e de redigir um relatório sobre esta ou aquela questão. Essa escolha se faz de maneira pragmática, no fim de uma discussão entre os membros da comissão e com base em critérios que podem variar segundo a figura escolhida. Na maioria das vezes, o relator é designado por seus conhecimentos ou sua proximidade com o assunto abordado. No entanto, no caso presente, parece que se procura mais a ingenuidade do relator. Portanto um ex-professor de Letras, então pouco familiarizado com as questões nucleares, foi encarregado para dirigir a reflexão exigida pelo primeiro-ministro. Se teve a oportunidade de interessar-se pelas questões energéticas no Conselho Regional do Nord-Pas-deCalais, Christian Bataille, deputado socialista eleito em 1988, é um autodidata nesse assunto. Ora, devido à postura de arbitragem que a comissão procura endossar, pode-se aventar a hipótese de que é justamente essa a sua principal qualidade. Assim como o longo afastamento do Parlamento da questão nuclear podia ser ostentado como uma garantia da independência de sua intervenção no assunto, a ingenuidade e a falta de competências técnicas do relator podem ser apresentadas como condições favoráveis para que o "espirito" esteja aberto aos atores em conflito.

No entanto, esse papel de "cândido" não é dado para sempre. Ao longo das consultas públicas, o relator esforça-se para modelar seu papel de árbitro e preservar, a todo custo, sua imagem de independência. Há suspeita de qualquer forma de conivência entre os parlamentares da OPl:CST e o governo? Ele cuida imediatamente de dissipar qualquer mal-entendido a respeito, se preciso, destacando-se claramente do governo e lembrando que representa somente o "Parlamento que, em plena liberdade está efetuando consultas para redigir um relatório que talvez seja lido pelos Poderes Públicos e do qual talvez tirem-se algumas conclusões" (p. 127). ${ }^{22}$ Em cada ocasião, o relator trabalha sua "apresentação de si mesmo", (re)define seu papel e o comunica aos seus interlocutores, por exemplo, lembrando várias vezes às pessoas consultadas que ele não está ali para expressar uma opinião, "mas somente para fazer perguntas" ( $p$.

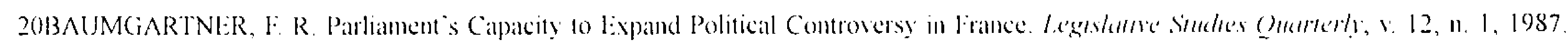

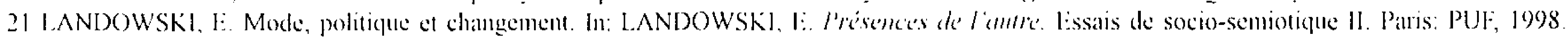

22 Para tornar a leitura mais leve. os trechos cilados seguidos de um simples numero de pagina remetem ao relatório da Comissào Parlamentar e ao relatório integral

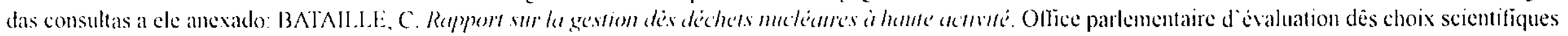
at echologicues, $\wedge$. N. 11. 18.39, Seinat n. 184, 1990. 
128). Em suma, o relator vai desenvolver toda uma "estratégia da neutralidade"23 para dar credibilidade à imparcialidade de sua ação e, de modo mais geral, do processo consultivo. Porém, essa estratégia da neutralidade não se apóia, aqui, em uma retórica da cientificidade; ela se traduz mais em uma valorização da discussão e do esclarecimento recíproco, em um respeito ostensivo à pluralidade dos pontos de vista, sejam eles científicos ou não, o que leva o relator a reconhecer, de antemão, que, a despeito de certo número de opiniões científicas antes favoráveis à estocagem geológica, "há opiniões divergentes", e a afirmar que ele "quer sobretudo evitar investir-se do valor da ciência, que é incontestável, para extrair dela um argumento" (p. 135). Por meio dessa reverência ostensiva à divergência das opiniões, privilegiase claramente aqui, uma nova maneira de conclusão da controvérsia. Para desfazer o conflito, não se trata de remeter a uma verdade científica transcendente, capaz de produzir um acordo entre os diferentes protagonistas. Se a existência de divergências científicas está sendo destacada, não é para ressaltar a falta de maturidade do conhecimento científico sobre o assunto, mas para justificar o recurso ao debate, o enriquecimento "externo" do problema pela integração dos mais diversos pontos de vista. ${ }^{2+}$ A objetividade reivindicada pelo relator não se apóia, então, em um princípio superior e universal, o conhecimento científico, mas, ao contrário, leva em consideração subjetividades contrastadas. É por isso que o processo de consulta concede legitimidade às "implicações polemistas" do problema, para retomar o neologismo de Alberto Cambrosio e Camille Limoges. ${ }^{25}$

\section{Uma "reprodução" da controvérsia}

A segunda característica do processo de consultas públicas é, efetivamente, o fato de não estar afastado das vicissitudes da controvérsia. Trata-se, ao contrário, de organizar um "fórum hibrido"?", repatriando o conflito em um âmbito institucional e, por assim dizer, reproduzi-lo em escala menor por meio de uma seleção de portavozes que supostamente representam a paleta dos grupos envolvidos. O espaço público da consulta não tem, portanto, características de um fórum de peritos, no qual seria apresentado e avaliado o estado dos conhecimentos sobre as possiveis conseqüencias de $\mathrm{um}$ enterramento do lixo atômico. Essa concepção ortodoxa da avaliação tecnológica é substituída, aqui, por uma abordagem que quer ser mais "participativa", estando nisso em conformidade com a tendência geral que caracteriza a prática desse tipo de avaliação em muitos países europeus. ${ }^{27}$ Mais do que recorrer somente à perícia científica para escapar às turbulências da controvérsia, trata-se de criar um espaço de debate no qual os argumentos gerados pela perspectiva do enterramento possam ser articulados de maneira exemplar. É por isso que, ao lado de alguns especialistas "históricos" na questão, que já participaram de trabalhos de perícia sobre o assunto e sobre os quais voltaremos a falar, há doravante lugar para os porta-vozes dos grupos mais diretamente envolvidos na estocagem geológica e que se constituíram através do próprio processo da controvérsia. $O$ dispositivo das consultas públicas, assim, opera aproximações inéditas e, na lista dos participantes (aproximadamente 40 , no total), encontram-se, lado a lado, os responsáveis das agências nucleares, as autoridades locais dos departamentos selecionados e os representantes de associações locais opostas ao projeto.

Essa heterogeneidade dos participantes é, evidentemente, apresentada como uma garantia da abertura do debate; e quer ser a tradução social da preocupação em restituir o conjunto dos pontos de vista que podem ser adotados sobre a questão, respeitando a igualdade de oportunidade de todos os argumentos. À medida que os interventores se sucedem, passa-se, alternadamente, dos problemas de imagem dos departamentos que suposta-

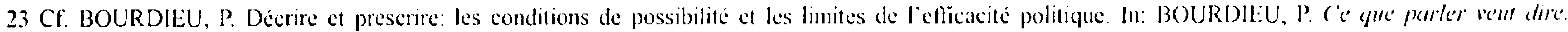
L"economie des échanges linguisticues. Paris: Fayard, 1982. p. 1998.

24 O processo aproxima-se, aqui, do "modelo do debate puiblico", descrito por Michel Callon. Cf. CAl. ON, M. Des diflerentes tormes de democratie technicue Ammalex dex mmex. Responsabilite et environnemut, n. 9, 1998.

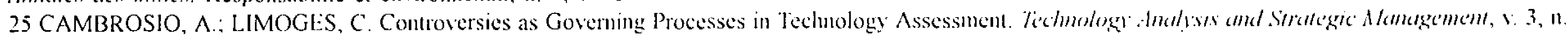
4,1991 .

26 Sobre a noçào de "förum hibrido", ver CALLON, M.: LASCOUMES, P.: BATHE, Y. fgrir dems am monde incerfam. Lessai sur la démocratie technicue. Paris: Seviil, 2001.

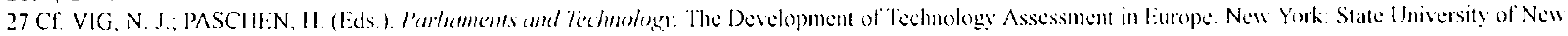
York Press, 2000 .
} 
mente acolherão um depósito de lixo atômico às vantagens e inconvenientes da estocagem nos fundos submarinos; do problema da responsabilidade moral perante as futuras gerações, às incertezas que envolvem a velocidade de circulação das águas subterrâneas; da organização institucional do setor nuclear na França, às possibilidades de incineração do lixo; dos processos de informação das populações mais diretamente envolvidas por uma eventual estocagem geológica, à definição dos reatores do ano de 2000 etc. A discussão ultrapassa continuamente a análise estrita dos perigos ligados ao enterramento, de modo que as consultas públicas assemelham-se a uma ampla mesa-redonda, permitindo arrolar os "problemas críticos" colocados pelo tratamento do lixo radioativo e estabelecer o mapa dos atores em conflito. Longe de ter como efeito restabelecer uma hierarquia dos argumentos em proveito do discurso científico, o processo, em suma, registra somente a "deshierarquização" dos problemas, operada pela controvérsia. ${ }^{2 x}$ A partir de então, a contribuição do conhecimento científico especializado sobre o assunto surge apenas como esclarecimento específico da questão, não parecendo nem mais nem menos legítimo do que outros.

Além disso, essa ausência de hierarquização não envolve somente a natureza dos problemas, mas também o tipo de racionalidade que deve prevalecer no tratamento da questão do lixo radioativo. Assim, quando o relator procura introduzir uma separação entre o que remete a uma argumentação "racional" e o que remete a um posicionamento "irracional", é convidado por alguns participantes a ultrapassar essa cômoda dicotomia em proveito do reconhecimento de uma pluralidade de registros de racionalidade. Por outro lado, o reconhecimento ao lado de uma racionalidade científica, de uma racionalidade "profana", ou, ainda, do que certos autores chamaram de uma "racionalidade do mundo cotidiano",2" é solicitado pelos participantes, que, por outro lado, reivindicam um ponto de vista "científico". É o caso, por exemplo, quando um representante do Grupo dos Científicos para a Informação sobre a Energia Nuclear (GSIEN) pleiteia a articulação entre um caminho científico e um questionamento que, embora remeta à "sabedoria popular", não é menos pertinente, a seu ver, na abordagem dos problemas colocados para o futuro a longo prazo do lixo atômico (p. 325). O processo de consultas públicas contribui, então, para visualizar e legitimar não somente os diversos problemas ligados à estocagem geológica, mas também a pluralidade dos sistemas de interpretação e dos registros de racionalidade envolvidos no conflito, o que tem por efeito fazer ruir o discurso de autoridade que poderia ser o da perícia científica.

\section{Um enquadramento do debate}

Se, então, as consultas públicas fornecem, no geral, uma boa representação do espaço da controvérsia, esta não é, no entanto, uma representação totalmente fiel. Doravante, de fato, o conflito encontra-se moldado em um formato específico e enquadrado por um processo de distribuição da palavra que contribui para modificar seu teor e permite ao relator controlar, permanentemente, a abertura do debate. É a terceira característica do processo que é preciso salientar: a inserção da controvérsia em um espaço institucional tem por corolário sua eufemização, o processo discursivo que caracteriza as consultas públicas tendo por efeito "domesticar", ousamos dizer, uma fala "selvagem" para substituí-la por uma fala "autorizada". No âmbito das consultas públicas, os argumentos não se desenvolvem de modo anárquico. $\mathrm{Na}$ verdade, os participantes não "tomam" a palavra, ela é "dada" por um presidente da sessão, o relator, cujo papel, por conseguinte, revela-se preponderante. Desde a primeira audiência, aliás, o relator define o sentido da interação e impõe as "regras do jogo": "para evitar qualquer diálogo ou qualquer forma de personalização deste debate, propõe-se aos senhores que se dirijam a mim por meio de um documento que encontrarão sobre a mesa e no qual estão convidados a escrever suas perguntas, e eu julgarei a oportunidade de colocá-las ou não" (p. 115). De resto, a própria organização do processo de consulta não permite a condução de um debate discrepante face a face, porque os participantes não estão reunidos todos ao mesmo tempo, mas se sucedem cada vez.

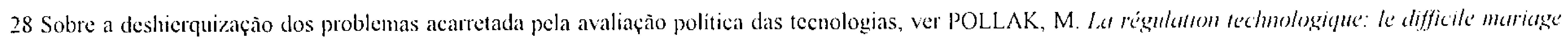
entre le droit at la kechmologice, art. citado.

29 Cf. GLOEDE, F. Tedmology Policy, Technolgy Assessment and Participation. In: SCHOMBERG, R. (Ed.). ('ontexted Techmolegri: lithici, Riks, amd l'ublic lehate. Tilburg: Intenational Centre for Human and Public Aflairs, 1995. 
Esse controle do processo consultivo traduz-se no decorrer das consultas de diversas maneiras, começando pela breve apresentação dos participantes. Antes de cada audiência, o relator lembra, em poucas palavras, a razão pela qual tal pessoa, a seu ver, merece ser ouvida. Define assim o direito de falar de cada participante e estabelece, ao mesmo tempo, uma distinção entre singularidades julgadas pertinentes - as que devem ser levadas em consideração no processo de avaliação do problema e que justificam que tal pessoa seja ouvida - e as distinções consideradas não pertinentes - as que, ao contrário, têm de ser ultrapassadas, tal como a filiação partidária das autoridades ouvidas, evitando assim, qualquer politização de cunho partidário do debate. Porém, o controle do presidente da reunião traduz-se sobretudo em um jogo de perguntas e respostas que molda o máximo possível a fala dos participantes. Após terem expressado seu ponto de vista, estes são intimados a responder às perguntas do relator, que, primeiramente, retoma de maneira geral a exposição inicial das pessoas ouvidas para esclarecer alguns pontos ou obter eventuais esclarecimentos. Depois, ele impõe seu próprio plano de questionamento. O termo "imposição" não é demasiado forte aqui, pois esse jogo de perguntas e respostas expressa bem uma relação de força em que predomina incontestavelmente o presidente da reunião, o qual, aliás, assinala no decorrer das audiências que "não está lá para dar perguntas de presente". Além disso, faz seus interlocutores compreenderem que não pretende se contentar com respostas evasivas. Se este for o caso, há repetição insistente das perguntas ou mesmo das advertências, ainda que expressadas sob a forma "eufemizada" de brincadeiras ou autozombarias ("noto que os senhores têm um belo futuro parlamentar porque não responderam a minha pergunta...", p. 128). Em outras palavras, o relator impõe-se como o detentor do que se pode chamar "o monopólio da questão legítima". Este monopólio pode se manifestar pela recusa em fazer uma pergunta recebida de um participante, sob a alegação de que ele a considera "um tanto polêmica e que ela não acrescentaria nada ao nosso dossiê" (p. 335). Às vezes, ao contrá- rio, manifesta-se pela manutenção de uma pergunta que a pessoa ouvida não julga pertinente. Assim, quando o administrador do CEA julga, no decorrer da audiência, que uma pergunta relativa ao "caso" dos despejos de Saint-Aubin e de Yteville no departamento da Essonne ${ }^{30}$ não corresponde "exatamente ao assunto da audiência", o relator considera, ao contrário, que "esta questão é interessante por mostrar o clima psicológico que vem sendo criado atualmente" (p. 274), lembrando implicitamente que ele é o único a determinar o enquadramento do problema.

Contudo, esse mecanismo de imposição permite ao relator, antes de mais nada, obrigar os participantes a abandonar as posturas "absolutistas", sejam elas morais ou científicas. Pois se o processo garante a todos os participantes o direito de serem ouvidos, impõe também, pelo viés das perguntas do presidente da sessão, o dever de participarem do processo coletivo de buscar soluções. Assim, embora os representantes das associações de proteção do meio ambiente pretendam limitar-se à expressão de uma recusa moral do enterramento, o relator leva-os incessantemente ao domínio da técnica e da segurança dos diversos modos de estocagem. De modo inverso, os responsáveis das agências nucleares vêem-se intimados a se justificarem no que diz respeito às decisões tomadas quanto ao manejo do lixo atômico, às pesquisas desenvolvidas e às que foram descartadas, ou ainda, à maneira como os aspectos "sociais" do problema foram levados em consideração ao longo do processo. Isso indica que o trabalho do relator não se limita a registrar os depoimentos de seus interlocutores e que o processo de consulta está longe de ser sinônimo de uma mera justaposição de pontos de vista irredutíveis. Com suas perguntas, o relator desempenha, na verdade, um papel de mediador do debate, incentivando os participantes a avaliar a dimensão plural do que está em jogo. Em suma, o questionamento do relator constitui um "foco de restrição": , para retomar a fórmula de Arie Rip, cujo efeito é estimular a articulação entre os diferentes aspectos do problema, transformar o conflito e direcioná-lo para um caminho mais construtivo.

30 Pouco antes das consultas publicas, o jonal / e larisien desencadeia uma polêmica ao revelar a contaminaçào de uma localidade do CEA no municipio de SaintAubin, no departamento da Essonne. Vestigios de plutônio foram encontrados em amostras de solo recollidas por dois jornalistas. Descobre-se então que lixo radioativo tinha sido depositado ali até 1973 e que alguns barris fechados com concreto foram rompidos pelo gelo, acarretando uma contaminaçào da localidade. Cf. le M/onk 2 nov. 1990.

3 I RIP, A. Controversies as Informal Technology Assessment. Khow/edge, v. 8, 17. 2, 1986. 


\section{Reversibilização e antecipação: a reconstituição de um espaço de escolha}

Até agora, a consulta pública organizada pela Comissão Parlamentar nos pareceu ser um meio de conciliar dois imperativos contraditórios: por um lado, restaurar a autoridade de uma instância política, canalizando o conflito e controlando a fala das diferentes partes interessadas e, por outro lado, ostentar o respeito pelo que surge, sob muitos aspectos, como um novo imperativo normativo, a saber, garantir que a diversidade dos pontos de vista seja levada em consideração. Tratar de maneira simétrica os que detêm um saber científico e técnico e aqueles que não o têm, conceder importância igual aos aspectos científicos e às dimensões "humanas" da questão, parecem ser as regras que devem presidir o tratamento do problema. No entanto, além desta constatação, uma questão não deixa de surgir: essa consulta se limita à encenação de um debate desapaixonado sem outro efeito, a não ser simbólico, de testemunhar as capacidades de escuta dos representantes políticos? Responder esta pergunta afirmativamente significa ignorar toda uma dimensão do dispositivo, a saber sua capacidade de fazer surgir soluções "praticáveis". O espaço público das consultas deve, na verdade, ser apreendido como um verdadeiro laboratório político no âmbito do qual são elaboradas formas de compromisso e onde são testadas futuras decisões. ${ }^{32}$ Para explorar esse aspecto construtivo do processo, é preciso voltar ao trabalho efetuado pelo relator. Mais exatamente, trata-se de entender como, nessa situação que parece saturada de irreversibilidades, tanto técnicas como sociais, o relator, não obstante, consegue encontrar margens de ação e "improvisar" certo número de medidas destinadas a recolocar em movimento essa política.

\section{O recurso à história ou a emergência de possí- veis nĩo ocorridos}

Essa "improvisação" passa primeiro por uma avaliação retrospectiva da política conduzida até então. $O$ desafio que esse recurso apresenta à história é conhecido, mas talvez seja preciso insistir no assunto; toda leitura do passado é também uma maneira de se apoderar do presente. Assim, a reconstituição do encadeamento de ações que levaram a uma situação conflituosa e percebida por muitos como um impasse assemelha-se, aqui, a um processo de "reversibilização" cujo efeito é, se não rejeitar, pelo menos tornar discutível o caráter inelutável da opção de referência constituída pelo enterramento e, justamente por isso, reencontrar certa "flexibilidade" na implementação dessa política. Nesse sentido, as consultas públicas não têm somente o objetivo de inventariar a diversidade dos pontos de vista que podem ser adotados sobre a questão, mas também, de identificar certo número de "anomalias" que podem dar lugar a medidas corretivas. Essa exigência de "correção da herança", segundo a expressão de François-Xavier Merrien, ${ }^{33}$ orienta a maneira como o relator redigirá seu relatório sobre essa política. Todo seu trabalho parece ser voltado para a necessidade de produzir uma história suscetível de fornecer "posturas" para futuras ações.

No decorrer das consultas, certo número de questões são levantadas, primeiramente a respeito da maneira como as pesquisas sobre a estocagem geológica foram inicialmente concebidas e desenvolvidas. Particularmente, o relator esforça-se para tornar discutível - e, portanto passível de revisão - o processo de seleção das quatro localidades a priori favoráveis ao enterramento. Essa questão está no cerne do intercâmbio com certas "testemunhas-chave" da etapa anterior, como o diretor da Andra, por exemplo: enquanto ele lembra as "limitações científicas" que pesaram nessa seleção, o relator, por seu lado, tenta, incessantemente, dar crédito à idéia de que a "paleta" pode ser ampliada, sugerindo, com isso, que as limitações científicas também podem ser discutidas. Na consulta ao representante do

32 Sobre esse aspecto dos processos consultivos, ver BACHIR, M. La consultation publicule. Nourel outil de gouvernabilite et transformation des registres et

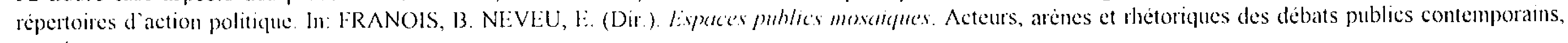
op. cit.

33 MERRII:N, F. X. Les politiques publiques entre paradignes et controverses. In: CRESAl. Les raisons de l'action lublique. Entre expertise et débat. Paris: liarmaltam, 1993. 
ministro da indústria, o relator ressalta o fato de que essa seleção foi feita sem uma "contra-perícia", dando a entender que, se ela tivesse ocorrido, o resultado poderia ter sido diferente. Antes de tudo, a revelação, durante as audiências, da existência de um mapa, estabelecido no início da década de 80 , com as zonas geográficas suscetíveis de serem envolvidas nos trabalhos da Andra, mostra claramente que, se forem recolhidos dados geológicos mais amplos, outras localidades poderiam ser investigadas. Há, portanto, a hipótese de considerar um retorno, uma possibilidade, segundo a expressão do relator" de "reabrir o jogo", possibilidade tanto mais interessante porque o relator dá a entender, casualmente, que será "muito difícil voltar às quatro localidades previstas para a estocagem do lixo, porque o clima foi degradado por causa dos erros cometidos". 3.

Porém, a originalidade desse trabalho de "estabelecimento da contingência" deve-se ao fato de que ele não aborda somente as modalidades de implementação do enterramento, mas também, em certa medida ao menos, a própria solução técnica. Ao atribuir o fracasso da Andra à "gestão tecnocrática autoritária" que predominou até então, o relator é levado, ao mesmo tempo, a tornar visíveis e discutíveis as microdecisões, que restringiram pouco a pouco o leque das escolhas na questão. Ao mesmo tempo, ressurgem outros tantos possíveis que não se concretizaram: alguns pontos de "bifurcação" reaparecem, alguns caminhos não seguidos ressurgem para serem considerados e discutidos novamente. Assim, o segundo ponto de discussão, que perpassa todas as audiências e que também contribuirá para produzir contingências, diz respeito à concentração de esforços na opção pela estocagem geológica sem que fosse desenvolvido paralelamente o estudo de técnicas inovadoras, notadamente os processos de retratamento avançado e de transmutação do lixo. Uma comissão de peritos, reunida no início da década de 80 - a comissão Castaing - tinha insistido, na época, na necessidade de prosseguir as pesquisas que, mesmo se não levassem forçosamente a uma solução que permitisse dispensar a estocagem geológica, teriam, no entanto, a vantagem de simplificar muitos dos seus parâmetros. Ao reduzir a duração de vida do lixo, a transmutação permitiria, na verdade, modificar o horizonte temporal a ser levado em consideração na estocagem e reduzir assim as incertezas inerentes à geologia prospectiva. Os peritos da comissão Castaing não foram seguidos nesse ponto e, em 1990, no momento das consultas organizadas pela Comissão Parlamentar, o número de pesquisadores trabalhando nessas questões no Cl:^ não passa de 20, enquanto o orçamento dedicado a esses estudos desde 1983 chega apenas a 50 milhões de francos. "Esse "congelamento" foi realmente justificado? A resposta a essa pergunta varia de acordo com os peritos ouvidos. Alguns mostram-se sempre reservados no que diz respeito a essas técnicas, alegando que são necessárias pesquisas longas e custosas para fundamentar esperanças reais nesse tipo de processo. Não obstante, a exigência de reversibilização levará o relator a reatualizar o interesse por esse caminho de pesquisa, apoiando-se notadamente em antigos membros da comissão Castaing, na maioria das vezes situados à margem das agências nucleares. Durante as audiências, eles têm a oportunidade de reiterar algumas das suas recomendações: acontece, então uma verdadeira "reciclagem" $\$$ " de propostas anteriores que têm, aqui, uma segunda chance de serem acatadas. Assim, sem afirmar claramente que há uma alternativa para o enterramento, um deles sugere que há, no entanto, "portas abertas", "possibilidades de fazer outra coisa", e recomenda, para explorar essas possibilidades, "levar em conta o que diz o relatório Castaing" ( $p$. 195 e 197). O próprio Raimond Castaing aproveita sua audiência para ressaltar que não se implementou tudo o que era necessário para tratar da melhor maneira possível o problema do lixo e precisa que "há vias conexas que não são examinadas e que poderiam ser" (p. 249). Assim como a reconstituição do processo de seleção das zonas favoráveis para o enterramento permitiram alongar a lista das localidades potenciais, a volta às questões levantadas na época pela comissão Castaing é suficiente para ampliar as pistas a serem exploradas e para redefinir o problema como um problema de pesquisa. No

34 le Monde, 14 dec. 1990.

$35 \mathrm{~A} / \mathrm{T}$. Serences n. 747, 13 dec 1990.

36 Comparativamente, os efetivos mobilizados na Andra para traballar sobre a estocagem profiunda são, em 1990,80 pessoas (dos 250 funcionários da $\wedge$ gềcia), sem contar os pesquisadores mobilizados no ambito das parcerias. Em termos de orçancento, o custo dos estudos desemvolvidos pela Andra sobre estocagem geologica representa. somente pelo ano de 1990, mais de 200 milhós de francos (p. 296).

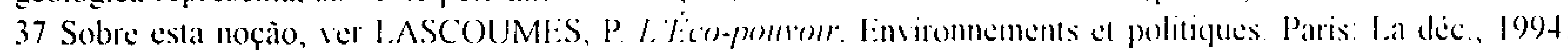


decorrer das audiências, constitui-se pouco a pouco um "reservatório" de medidas suscetíveis de tirar da estocagem geológica seu estatuto de opção única.

\section{A construção do aceitável: uma investigação técnica e politica}

O segundo aspecto da "improvisação" operada pelo relator remete mais a uma avaliação ex ante, que consiste em simular essas medidas concebíveis. Se o objetivo não é chegar forçosamente a um consenso, trata-se, no entanto, de determinar a lógica dos vários atores e incentivar um processo de aprendizagem a menor custo. Nessa ótica, as consultas públicas constituem uma ferramenta valiosa. Permitem o surgimento de propostas e a antecipação de seus efeitos junto aos vários grupos envolvidos, representados no âmbito do processo por seus respectivos porta-vozes. Ao fazer intervir atores com identidades radicalmente diferentes e com reivindicações tão heterogêneas quanto, as consultas permitem, ao mesmo tempo, integrar limitações técnicas de viabilidade e limitações políticas de aceitabilidade. O trabalho do relator traduz-se precisamente por uma tentativa de articular esses dois tipos de exigências, que, a priori, não parecem compatíveis. Como tornar a estocagem geológica politicamente aceitável? Como traduzir tecnicamente algumas exigências expressadas pelos representantes das populações envolvidas? Trata-se de encarar de frente essa dupla exploração, essa dupla investigação e, para tal, começar pela "deshomogeneização" desses dois blocos aparentemente homogêneos que se confrontaram na controvérsia. Ou seja, de um lado as populações determinadas a recusar a estocagem geológica, de outro os responsáveis pelo programa nuclear interessados apenas na opção do enterramento. Para reencontrar margens de ação e tentar fazer propostas que visem a reativar essa política, se irá, em suma, jogar nos "interstícios" tanto do projeto técnico como do seu "ambiente".

Nas propostas formuladas pelo relator, bem como na sua maneira de conduzir as audiências, reencontrase, aliás, um dos repertórios clássicos de ação no que diz respeito ao tratamento dos conflitos suscitados pelo programa nuclear, a saber, a "desconstrução" do movimento contestador em uma pluralidade de atores e a seleção dos representantes considerados mais "sensatos" ou mais moderados. Observemos que a própria organização das consultas públicas tende a induzir esse tipo de efeito: ao dar a palavra a vários porta-vozes, ela leva à apresentação de uma imagem mais matizada do movimento de oposição ao enterramento. As alianças que a controvérsia acabara por selar, notadamente entre associações e autoridades locais, tornam-se menos sólidas pelo simples fato do tipo de processo empregado. O relator reforça esse efeito de decomposição, ao fazer claramente, no decorrer da consulta, a divisão entre os representantes das associações contrárias ao enterramento e os parlamentares locais, apresentados, na ocasião, como a expressão mais legítima da população. Assim, quando um dos porta-vozes da coordenação contra o enterramento lembra que a oposição quanto às localidades selecionadas não é marca de uma minoria, mas da grande maioria da população, como tende a prová-lo o engajamento dos parlamentares, isto é, de qualquer forma, uma "armadilha" do relator, que devolve o argumento para valorizar a capacidade de representação dos próprios parlamentares, em detrimento da representação das associações.

É por isso que, se as consultas públicas apresentam-se primeiramente como uma tentativa de ultrapassar a democracia representativa tradicional, elas têm por efeito, paradoxalmente, recolocar os parlamentares como os principais interlocutores do poder público. Aqui também, o processo ainda é ambivalente; por um lado, permite abrir a discussão a uma pluralidade de representantes, por outro lado, leva a uma (re)hierarquização desses vários porta-vozes, em proveito da representação política tradicional. No presente caso, essa assimetria a favor dos parlamentares não remete somente ao respeito das regras "normativas" que estruturam o jogo político, mas também, para retomar a famosa distinção de Frederik Bailey, ${ }^{38}$ a respeito de uma regra "pragmática": trata-se de o relator ter de chegar a propostas de reforma e, nessa perspectiva, parece mais fácil achar alguns pontos de consenso com os parlamentares locais que se mostram mais propensos ao compromisso do que com os representantes das associações que ostentam uma oposição 
mais radical ao projeto e não deixam de ampliar sua crítica ao caminho nuclear como um todo. Assim, não surpreende mais constatar que a maioria das sugestões feitas pelos parlamentares ouvidos é retomada pelo representante da comissão na forma de recomendações que, supostamente, tornarão politicamente aceitáveis as pesquisas sobre a estocagem, como, por exemplo, a criação de comissões locais de informação sobre as localidades envolvidas, ou, ainda, a implementação de medidas "de acompanhamento econômico" do projeto.

Porém, as propostas do relator visam igualmente a encontrar uma tradução técnica para algumas exigências expressadas durante as consultas, notadamente a exigência de diversificação das pesquisas. Será que essa abertura pode ser encarada? Será que os processos alternativos mencionados nas audiências por alguns peritos podem ser novamente investigados? Essa possibilidade será testada junto aos atores mais suscetiveis de redefinir o direcionamento da pesquisa sobre esse assunto. Em particular, a questão é saber se as pesquisas sobre a transmutação podem ser reativadas e quais são as medidas necessárias para que isso seja feito. No decorrer das audiências, os representantes das diversas agências nucleares são levados a se empenhar nesse ponto e a se pronunciar claramente a respeito da retomada das pesquisas envolvendo essas técnicas inovadoras, cujo desafio, claramente assinalado pelo relator, é, sobretudo, "criar um clima que mostre que tudo está sendo feito no domínio científico para buscar as soluções mais satisfatórias no que diz respeito ao programa do enterramento" (p. 265).

A abertura das pesquisas sobre a questão do lixo atômico é, de resto, uma das principais recomendações que emanam do relatório da Comissão Parlamentar. Se a necessidade de levar adiante o programa relativo ao enterramento é igualmente sublinhada, essa abertura basta, contudo, para "ajustar" o caráter irreversível da estocagem geológica, que passa do estatuto de solução adquirida ao de mera opção de pesquisa, discutivel por definição e que deve ser submetida a pacientes investigações científicas. A mudança é enorme, porque, com esse reenquadramento, estamos novamente no âmbito de um processo de "preparação" de uma decisão e não mais de sua implementação. A lei de 30 de dezembro de 1991, que se seguiu à consulta organizada pela comissão e que se apóia, em grande parte, nas recomendações formuladas pelo seu relator, confirma essa mudança de quadro de referência, já que se escolheu um caminho experimental: a decisão definitiva quanto à solução a ser privilegiada para tratar o problema do lixo atômico de vida longa está, de fato, adiada para uma data posterior, em proveito de uma dupla experimentação: experimentação, em primeiro lugar, científica, que se articula em várias opções de pesquisa; experimentação política, em seguida, amparada na implementação de toda uma série de processos de consulta e informação em plano local, em todas as localidades suscetiveis de serem envolvidas em uma eventual estocagem. No inicio, essa legislação "modesta", que adia a hora da escolha definitiva, pode ter sido interpretada como uma estratégia política que visa a criar algo irreversivel com "pequenos passos" ao adotar um caminho mais progressivo sem, para tal, modificar os objetivos iniciais. Porém, a história dessa política mostra que o tempo também desempenhou seu papel como criador de incertezas. Assim, longe de ter tido como efeito encerrar o debate, essa mudança de estilo de governar contribuiu para transformar o jogo de maneira duradoura e, para falar como Norbert Elias, para alongar as cadeias de interdependência. Essa abertura traduziuse, em primeiro lugar, na intervenção de atores até então excluídos do processo de decisão, particularmente os parlamentares que, em favor da publicidade doravante concedida a essa politica, ingressam regularmente no cerne dos debates relativos às orientações de pesquisa e reativam permanentemente a controvérsia. Ela se traduziu, também, em uma revitalização da pesquisa nesse domínio, pois novos atores científicos tomaram para si as possibilidades oferecidas pela lei de entrar no "jogo" da produção científica e tecnológica relativa ao lixo atômico e de explorar novos caminhos de pesquisa.

No fim deste estudo de caso, seria vão pretender extrair ensinamentos gerais sobre os processos consultivos. Contudo, a análise das consultas públicas organizadas sobre a questão do lixo atômico permite matizar a interpretação geralmente dada a esse tipo de dispositivo. Na verdade, como sugerimos várias vezes neste artigo, o desafio dos processos consultivos que vêm se desenvolvendo hoje em dia nas políticas públicas não é apenas conter as controvérsias e superar as "resistências" que certas decisões podem suscitar. O recurso a esse tipo de técnicas de governo é também o meio pelo qual os representantes políticos podem reapropriar-se de alguns problemas, antes tratados em espaços confinados, ostentando, desse modo, a preeminência do político fren- 
te à competência do erudito ou do técnico. Os novos espaços de debate, que vêm se abrindo em domínios tradicionalmente geridos por instâncias especializadas, são, em outras palavras, a oportunidade para que os representantes politicos reafirmem sua autoridade e a especificidade de seus próprios critérios de escolha. Nas situações de trancamento tecnológico, essa "inserção na política", que não se confunde necessariamente com uma "politização", no sentido de confronto entre facções partidárias, tendo em vista a aquisição de cargos, passa pela abertura de um espaço de possibilidades, unicamente capaz de dar crédito à idéia que os "decididores" políticos podem influenciar mesmo na decisão. É por isso que, nessas situações, podemos di-

\section{REFERÊNCIAS}

AFP. Sciences. n. 747.13 déc. 1990.

ARTHIUR. B. W. Competing lechnologies. Increasing Returns. and lock-in by I listorical livents. The liconomic Joumnal. n. 99. 1989.

BACIIIR. M. La consultation politique. Nouvel outil de gouvernabilité et transformation des registres d'action publique. In: IRRANÇOIS. B.: NI:VIIU. I: (Dir.). Lspaces publics mosaíques. Acteurs. arènes et rhétoriques des de bats publics contemporains. Rennes: Presses universitaires de Rennes. 1999.

BAILEY. I. G. Les régles du jél politique. Étude anthropologique. Paris: PUI: 1971.

BOURDIEZU. P. Décrire et preserire: les conditions de possibilité el les limites de leflicacité politique. In : ce que parler veut dire. Leconomie des échanges linguistiques. Paris: Fayard. 1982. p. 1998.

BARRI:RE. M. La doctrine nucléaire contre vents et marées. In: FERME. G. (Dir.). Science, pouvoir et argent. La recherché entre marché et politique. Paris: Autrement. 1993. (Série Sciences en société. n. 7).

BATAIILL. C. Rapport sur la gestion dês déchets mucléaires à haute activité. Ollice parlementaire dévaluation dês choix scientifiques el technologiques. AN. n. 1839. Sénat n. 184. 1990 zer que tornar governável é, em primeiro lugar, tornar discutivel e, no caso, abrir a "caixa-preta" das heranças tecnológicas. Certamente, convém questionar, dependendo do caso, a realidade dessa abertura e seus efeitos. Porém, ao mesmo tempo, é todo um questionamento empírico que se configura e que permite sair das considerações abstratas e gerais sobre a democracia deliberativa. Ao atentar na constituição de espaços públicos específicos, há de se questionar os processos, mas também, as estratégias e os recursos mobilizados pelos atores, para aumentar o grau de discutibilidade dos problemas e mantê-los, assim, na agenda das autoridades públicas, ou, ao contrário, desencadear mecanismos de fechamento e de irreversibilização.

BAUMGARTNI:R. F, R. Parliament's Capacity to Expand Political Controwersy in France. Legislative Studies Quarterly. 1. 12. n. 1.1987.

BL ATRIX. ('. la "démocratie participative", de mai 68 an. mobilisations anti-T(jl. Processus de consolidation d'institutions sociales emergentes. Tese (Doutoramento $\mathrm{cm}$ (iência Política) - Université de Paris I. 2000.

BL.ONDIAUX. L. L a délibération, norme de l'action publique contemporaine"?. Projet. n. 268.2001.

BOYIER. R.: (HIACANCI: B.: (OODARD). (). (Dir.). Les figures de l'irreversibilité e'm économie. Paris: Bditions de

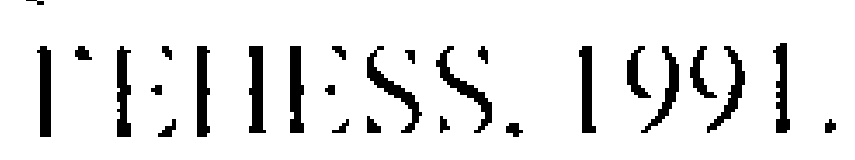

CALI.ON. M. Des différentes formes de démocratie technique. Innales des mines. Responsabilité et environnemnt. n. 9. 1998.

CALION. M.: LASCOUMLS. P.: BATHE. Y. Agir dans un monde incertcin. Lsssai sur la démocratie technique. Paris: Seuil. $2(0) 1$.

CALLON. M. Pour une sociologie des controverses technologiques. Findamenta Scientiae. v. 2. n. 3-4. 1981.

CAMBROSIO. A.: I.IMOGLS. C. Controversies as Governing Processes in Technology Assessment. Technology Analysis and Strategic .1 Kanagement. v. 3. n. 4. 1991. 
CHAMBAT. P.. Fourniau. J. M.. Débat public et participation démocratique. In: VALLLI:MONT (Dir.). Le débat public: une réforme dans l'Etat. Paris: LGDJ.. 2001. p. 35.

CORCUFF. P.: SANIER. M. Politique publique et action stratégique em contexte de décentralisation. Aperçus d'um processus décisionnel 'après la bataille. Annales HSS, v. 55, n. 4. 2000.

COWAN. R. Nuclear Power Reactors: $\Lambda$ Study in Technological Lock-in. Journal of Economic History. v. 5. n. 3, 1990.

DAVID. P. Clio and the Economics of QWERTY. American Economic Review. n. 75. 1985.

DEFRANCE. J. Donner la parole. La construction d'une relation d'échange. Actes de la recherche en sciences socials, n. 73.1988

FINON. D. L'échec des surgénérateurs. Autopsic d'un grand programme. Grenoble: Presses universitaires de Grenoble. 1989

GLOEDE, F. Technology Policy. Technolgy Assessment and Participation. In: SCIIOMBERG, R. (Ed.). Contested Technology: Ethics, Riks, and Public Debate. Tilburg: international Centre for lluman and Public Affairs, 1995.

HIRSCHMAN. A. O. Deux siècles de rhétorique réactionnaire. Paris: Fayard. 1991.

JOBERT. B. Représentations sociales. controverses et débats dans la conduite des politiques publiques. Revue française de science politique. v. 42. n. 2. 1992.

JOSS. S.: DURAND. J. (Eds.). Public Participation in Science. The Role of Consensus Conlerences in Europe. L ondon: Science Muscum. 1995.

JOSS. S. (Ed.). Special Issuc on Public Participation in Science and Technology. Science and Public Policy. v. 26, n. 5. 1999.

KEMP. R. Planning. Public Ilearings. and the Politics of Discourse. In: FORIESTER. J. (lid.). Critical Theory and Public Life. Cambridge: MIT Press. 1985.

LANDOWSKI. E. Mode. politique et changement. In: E. Présences de l'antre. Lissais de socio-semiotique ll. Paris: PUF. 1998.

LASCOUMES. P. L'Éo-powroir: Environnements a politiques. Paris: La Découverte. 1994.

. Rendre gouvernable: de la "traduction" au "transcodage". L'analyse des processus de changement dans les réseaux d'action publique. In: CURAPP. (Ed.). La gouvernabilité. Paris: PUF. 1996.

LEMONDE. 14 déc. 1990.

LEVIDOW. L. Democratizing Technology or Technologizing Democracy? Regulation Agricultural Biotechnology in Lurope. Technologv in Society. n. 20. 1998.

MANIN. B. Volonté générale ou delibération ? Esquisse d'une théorie de la délibération politique. Le Débat. n. 33. 1985. p.89.

MIERRIIEN. F. X. Les politiques publiques entre paradigmes et controverses. In: CRESAl. Les raisons de l'action publique. lintre expertise el débat. Paris: l harmattan. 1993.

PALIER. B.: BONOI.I. G. Phénomines de path dependence et réformes des systemes de protection sociale. Revue firançaise de science politique. v. 49. n. 3. 1999.

PIIERSON. P. When liflec Becomes Cause: Policy Feedback and Political Change. Horld Politics. v. 45, n. 4. 1993.

Increasing Returns. Path Dependence and the Study of Politics. American Political Science Review. v. 94. n. 2. 2000.

POLL ACK. M. La régulation technologicue: le diflicile mariage entre le droil et la technologic. Revute fiançaise de science politicule, v. 32, n. 2.1982

RENN. O.: WIEBLER. T.: WIIEDEMANN. P. (lids.). Fairness and Competence in Citizen Participation. Evaluating Models for Environmental Discourse. Dordrecht: Kluwer Academic Publishers. 1995

RIP. A. Controversies as Informal Technology $\Lambda$ ssessment. Kinowledge. v. 8. n. 2.1986.

ROWI: (i.: FRI:WER. L. J. Public Participation Methods: A Framework for Ivaluation. Science. Technology and Ituman lalues. v. 25, n. 4. 2000.

SCLOVI: R. I: Democracl and Technology. New York: The Guilford Press. 1995

VIG. N. I.: PASCIII:N. II. (I:ds.). Parlicmems and Techmologl: The Development of lechnology $\wedge$ ssessment in liurope. New York: State Universily of New York Press. 2000.

WALKl:R. W. Entrapment in large Technology Systems: Institutional Commitment and Power Relations. Research Policy. v. 29. n. 7-8. 2000. 